\title{
IMPORTANCE OF SCREENING IN THE PREVENTION OF EMERGENCE AND SPREAD OF MDR BACTERIA
}

\author{
Fatima Numanović', Jasmina Smajlović', Elsada Čičko², Zineta Delibegović' \\ Hanka Kikanović́, Amela Bećirović́, Emir Halilović', Mubera Kutlovac ${ }^{1}$, Indira Džanićc ${ }^{3}$
}

(C) 2019 by Acta Medica Saliniana ISSN 0350-364X

DOI: $10.5457 / 522$

Fatima Numanović Jasmina Smajlović Elsada Čičko

Zineta Delibegović

Merima Gegić

Hanka Kikanović

Amela Bećirović

Emir Halilović

Mubera Kutlovac

Indira Džanić

\begin{abstract}
Background: Colonization is the presence of bacteria in the intestines, skin, nose, throat or anywhere in the human body without any signs of infection but with increased risk for spreading bacteria to other patients and the emergence of new infections. Screening of colonized patients is used as part of the prevention and control of multidrug-resistant (MDR) infections caused by agents such as methicillin-resistant Staphylococcus aureus, vancomycin-resistant Enterococcus faecalis and multi-resistant Gram-negative bacteria.

Material and methods: Data from 169 screened respondents hospitalized at the University Clinical Center Tuzla, between October 1, 2018, and May 1, 2019, were analyzed. Swabs were taken from nostrils, throat, axilla and groin area for all patients, and also from the anorectal area for 157 of them. Identification of MDR bacteria was done by phenotypical methods, according to the recommendations of EUCAST Clinical Breakpoint Table v.8.o, 2018.

Results: Out of 169 patients, negative screening test results were found in 93 examinees $(55.02 \%)$, and positive in $76(44.97 \%)$. The largest number of patients undergoing screening was hospitalized in the Intensive Care Unit (Surgical Block), 73/169 (43.19\%). The average screening time was 2.2 days or 53 hours. In $18 / 76$ (23.68\%) of patients with positive screening, prior to screening regular microbiological testing was done, and in the remaining $58 / 76(76.3 \%)$ screening was performed first. Analyzing respondents with positive screening, $27(35.53 \%)$ had negative findings during regular microbiological testing of different biological samples and for $49(64.47 \%)$ different/same strains of MDR bacteria were isolated.

Conclusion: Knowing the phenotypic profile of bacteria colonizing patients in intensive care units is a very useful tool in preventing their spread intra- and interhospitals.
\end{abstract}

Key words: screening, multi-resistant bacteria, ESBL, MRSA, CARBA, AmpC

\section{INTRODUCTION}

MDR (multidrug-resistant) bacteria are defined as bacteria with acquired resistance to at least one antibiotic from three or more antibiotic classes and are often responsible for infections associated with healthcare facilities [1]. Infections caused by MDR Gram-negative and Grampositive bacteria are difficult to treat and can cause additional problems to patients such as slow wound healing, pneumonia or sepsis. This may extend the duration of the hospital stay and in some cases, it may cause death outcome. Continuous antibiotic pressure in hospital and outof-hospital environments selects resistant bacteria such as those that represent part of normal microbial flora (colonization), as pathogenic bacteria. It has been shown that for each day of antibiotic use, the risk of infection increases by $2 \%$ in hospital and $1 \%$ in out-of-hospital facilities [2]. Colonization/infection with MDR bacteria is associated with the use of quinolones, third and fourth generations of cephalosporins and carbapenems [3]. Significant risk factors for colonization/ infection with carbapenem-resistant Klebsiella pneumoniae (K. pneumoniae) represent the use of catheter and poor overall health status of patients with low functional status, which is also associated with the stay at long-term healthcare facilities [4]. For colonization or infection with extended-spectrum beta-lactamase (ESBL) producing bacteria, additional risk factors are the presence of gastrostomy tube, urinary catheter, nasogastric probe as well as the length of their application [5]. 
Colonization is the presence of bacteria in the intestines, skin, nose, throat or anywhere in the human body without any signs of infection, but with increased risk for spreading bacteria to other patients and the emergence of new infections. The spread of resistant bacterial types from patient to patient is mainly via the hands of medical personnel and from sources in the patient environment such as contaminated ventilation equipment or drinking water supply systems (faucets or water purifiers).

Prevention and control of MDR bacteria spread is based on regular hand hygiene, the use of proper personal protection, and a well maintained and clean patient environment in the hospital. Patient screening is used as part of the prevention and control of MDR infections caused by agents such as methicillin-resistant Staphylococcus aureus (MRSA), vancomycin-resistant Enterococus faecalis (VRE), and multi-resistant Gram-negative bacteria (Extended Spectrum Beta-lactamases; ESBL), cephalosporinase (AmpC - plasmid-mediated AmpC beta-lactamase) and carbapenem-resistant bacteria (CARBA), excluding Salmonella and Shigela. It is effective in early identification of the problem of resistance spreading, efficient resolution of this problem through pathogen identification, isolation or cohorting of patients and later decolonization. Awareness of colonization is important and, therefore, the identification of those colonized with MDR strains is of critical importance for intra- and inter-hospital transfer of patients. Screening and isolation of patients with MDR bacteria result in significant cost increases in institutions where they are not practiced but these costs may be significantly reduced if applied mainly due to the reduced spread of resistant bacteria and fewer cases where antimicrobial therapy is needed [6].

To prevent the spread of MDR bacteria, there are guidelines at the level of each country that provide advice on screening, treatment of infections and measures to prevent their spread, as well as prescribing and managing antimicrobial agents. The aim of the study was to determine the importance of screening in the emergence and spread of MDR bacteria by determining the number of patients with positive screening test results compared to the total number of screened patients, identification of the phenotype of isolated bacteria with the antibiotic profile, as well as the percentage of transmission of isolated MDR bacteria from colonization site to the emergence of infection in the same patient.

\section{MATERIAL AND METHODS}

The research was retrospective-prospective and covered the period from October 1, 2018 to May 1, 2019. The data from 169 respondents screened at the Institute of Microbiology, Polyclinic for Laboratory Diagnostics, University Clinical Center Tuzla (UCC) during the study period, were analyzed. Swabs were taken from nostrils, throat, axilla and groin area for all patients, and also from the anorectal area for 157 of them. The aforementioned respondents were hospitalized at different departments of University Clinical Center Tuzla: Intensive Care Unit - Surgical Block, Intensive Care Unit - Blue Building, Department of Hepato-Pancreato-Biliary Surgery; Department of Colorectal Surgery, Department of General Abdominal Surgery, Department of Lung Surgery, Department of Vertebrology, Department of Children's Orthopedics, Orthopedic Traumatology Department, Department for Septic States, Department of Aloplastics and Sport Trauma and Clinic of Hematology. Respondents were divided into two groups: Group 1 included subjects with negative screening test results, and Group 2 included subjects with positive screening test results.

Laboratory detection of ESBL-producing Enterobacterales, CARBA-producing Acinetobacter spp. and MRSA was performed by phenotypic methods. Samples taken from each examinee were cultivated on blood agar, Endo agar, and glucose broth. Following the incubation under aerobic conditions for 24 hours at $37^{\circ} \mathrm{C}$, identification of an isolated strain was performed to the species level, and depending on the type of isolated bacterium, an initial screening for MDR bacteria was performed by testing antimicrobial susceptibility by disk diffusion and microdilution methods (using VITEK 2 Compact, automated instrument, bioMèrieux, France), in accordance with institution's official procedures. The suspected presence of ESBL producers was based on the existence of synergism between the thirdgeneration cephalosporins and amoxicillin/clavulanic acid disks as well as the inhibition zone diameter value for ceftazidime $(10 \mu \mathrm{g})<22 \mathrm{~mm}$, ceftriaxone $(5 \mu \mathrm{g})$ $<23$, cefotaxime $(5 \mu \mathrm{g})<21 \mathrm{~mm}$ and cefpodoxime (10 $\mu \mathrm{g})<21 \mathrm{~mm}$. In addition to the disk diffusion method, ESBL isolate detection was done by Vitek 2 Compact instrument, which identifies the phenotype and determines the minimum inhibitory concentration (MIC). Identification of ESBL producers was confirmed when MIC for above-mentioned antibiotics was as follows: cefotaxime/ceftriaxone and ceftazidime MIC>1 mg/L as well as for cefpodoxime MIC>1 mg/L. Each positive isolate was also cultured on chromogenic media for ESBL screening (bioMerieux, France). The growth of dark red to reddish colonies verified the identification of ESBL-producing Escherichia coli (E. coli), and metallic blue colonies ESBL-producing Klebsiella, Citrobacter and Enterobacter.

Using the same test we also determined the presence/ absence of AmpC producers. When the diameter for ceftazidime, cefotaxime, ceftriaxone was within the zone of resistance, there was no synergism with clavulanic acid, and the isolate resistant to cefoxitin with a zone of inhibition of $\leq 19 \mathrm{~mm}$ was considered a AmpC $\beta$ lactamase producer.

Screening test for the detection of carbapenemaseproducing Enterobacterales (CPE) was performed by disk diffusion method using meropenem disk (10 
$\mu \mathrm{g})$. Carbapenemase-producer testing was considered justified if the inhibition zone diameter for meropenem was $<25 \mathrm{~mm}$. Screening cut-off for the presence of carbapenemase-producing Enterobacterales was considered positive if the inhibition zone for meropenem was $<28 \mathrm{~mm}[7]$.

Detection of carbapenemase-producing Acinetobacter spp. and Pseudomonas aeruginosa (P. aeruginosa) was performed by disk diffusion susceptibility testing to meropenem $(10 \mu \mathrm{g})$ and, after obtaining positive results (resistance to meropenem), by phenotypic resistance type identification by VITEK 2 Compact (card AST-N232) and MIC determination for meropenem. If the inhibition zone diameter values for Acinetobacter spp.) were below $15 \mathrm{~mm}$ by disk diffusion method or MIC above $8 \mathrm{mg} / \mathrm{L}$, and for $P$. aeruginosa below $18 \mathrm{~mm}$ or MIC over $8 \mathrm{mg} / \mathrm{L}$, we considered that the isolate was a carbapenemase-producer. Each positive isolate tested for carbapenemase-resistance was transferred to a chromogenic carbapenemase CHROMID CARBA resistance detection medium (bioMerieux, France). In agreement with the manufacturer's guidelines, only blue colonies were considered to be suspected Enterobacterales and white (i.e., colorless) colonies were considered to be Acinetobacter [8].

The first indication of MRSA presence was the resistant result to cefoxitin $(30 \mu \mathrm{g})$, by disk diffusion and microdilution methods. $S$. aureus with inhibition zone for cefoxitin of $<\mathbf{2 2} \mathbf{m m}$ and MIC $>4 \mathrm{mg} / \mathrm{L}$ was reported as methicillin-resistant. After confirming the presence of MRSA, the same isolate was transferred to a chromogenic CHROMID MRSA agar (bioMerieux, France). Seeded plates were incubated for 24 hours at $35^{\circ} \mathrm{C}$. MRSA positive strains were reported if single green colonies were detected, while no growth observed was considered MRSA negative sample. MRSA strain phenotype verification was performed by automated procedure on VITEK 2 Compact, using AST-P 580 and AST-P586 susceptibility cards.

For each isolate a complete antibiogram was done using Kirby-Bauer disk diffusion test and values recorded according to the recommendations of EUCAST Clinical Breakpoint Tables v. 8.o, valid from 2018-01-01. For Enterobacterales susceptibility to ampicillin (10 $\mu \mathrm{g})$, amoxicillin/clavulanate
(30 $\mu \mathrm{g})$, ceftazidime (10 $\mu \mathrm{g})$, cefuroxime (30 $\mu \mathrm{g})$, cefotaxime $(5 \mu \mathrm{g})$, cefepime $(30 \mu \mathrm{g})$, amikacin $(30 \mu \mathrm{g})$, gentamicin $(10 \mu \mathrm{g})$, tobramycin $(10 \mu \mathrm{g})$, trimethoprim/ sulfamethoxazole $(25 \mu \mathrm{g})$, ciprofloxacin $(5 \mu \mathrm{g})$, levofloxacin $(5 \mu \mathrm{g})$, imipenem $(10 \mu \mathrm{g})$, meropenem (10 $\mu \mathrm{g})$, colistin $(10 \mu \mathrm{g})$, ampicillin/sulbactam (10/10 $\mu \mathrm{g})$ and rifampicin $(5 \mu \mathrm{g})$ was examined. For Acinetobacter susceptibility to imipenem (10 $\mu \mathrm{g})$, meropenem (10 $\mu \mathrm{g})$, ciprofloxacin $(5 \mu \mathrm{g})$, levofloxacin $(5 \mu \mathrm{g})$, amikacin (30 $\mu \mathrm{g})$, gentamicin (10 $\mu \mathrm{g})$, tobramycin (10 $\mu \mathrm{g})$, trimethoprim/sulfamethoxazole $(25 \mu \mathrm{g})$, colistin (10 $\mu \mathrm{g})$, ampicillin/sulbactam (10/10 $\mu \mathrm{g})$ and rifampicin (5 $\mu \mathrm{g})$ was investigated $[7,9]$. According to the EUCAST recommendations, colistin sensitivity was determined by MIC breakpoints (mg/L). Because of the high cost of the E test, in our lab colistin sensitivity for CARBAproducing Acinetobacter and Klebsiella pneumoniae was determined based on MIC breakpoints using VITEK 2 Compact system, after the disk diffusion method. Acinetobacter spp. was considered colistin sensitive by disk diffusion method if the inhibition zone was $\geq 14$ $\mathrm{mm}$, while K. pneumoniae and Enterobacter spp. were considered sensitive for colistin if the inhibition zone was $\geq 14 \mathrm{~mm}$, and resistant if it was $\leq 11 \mathrm{~mm}$. [10, 11]. For all samples for which the inhibition zone was $\leq 14 \mathrm{~mm}$, MIC was verified by VITEK 2 Compact system.

\section{Statistical analysis}

For statistical data processing we used the methods of standard descriptive statistics: Student t-test and Chi square test. The value of $\mathrm{p}<0.05$ was considered statistically significant. The data were processed in the statistical program IBM SPSS 20.0.

\section{RESULTS}

Out of a total of 169 patients, negative screening test results were obtained for $93(55.02 \%)$ and positive for $76(44.97 \%)$ examinees. The largest number of patients undergoing screening was hospitalized at the Intensive Care Unit - Surgical Block 73/169 (43.19\%), followed by the Department of Hepato-Pancreato-Biliary Surgery $44 / 169(26.03 \%)$ and the smallest number at the Department of Children's Orthopedics, the Intensive Care Unit - Blue Building, and the Department of Aloplastics and Sport Trauma, 2/169 (1.18\%) for each (Figure 1).

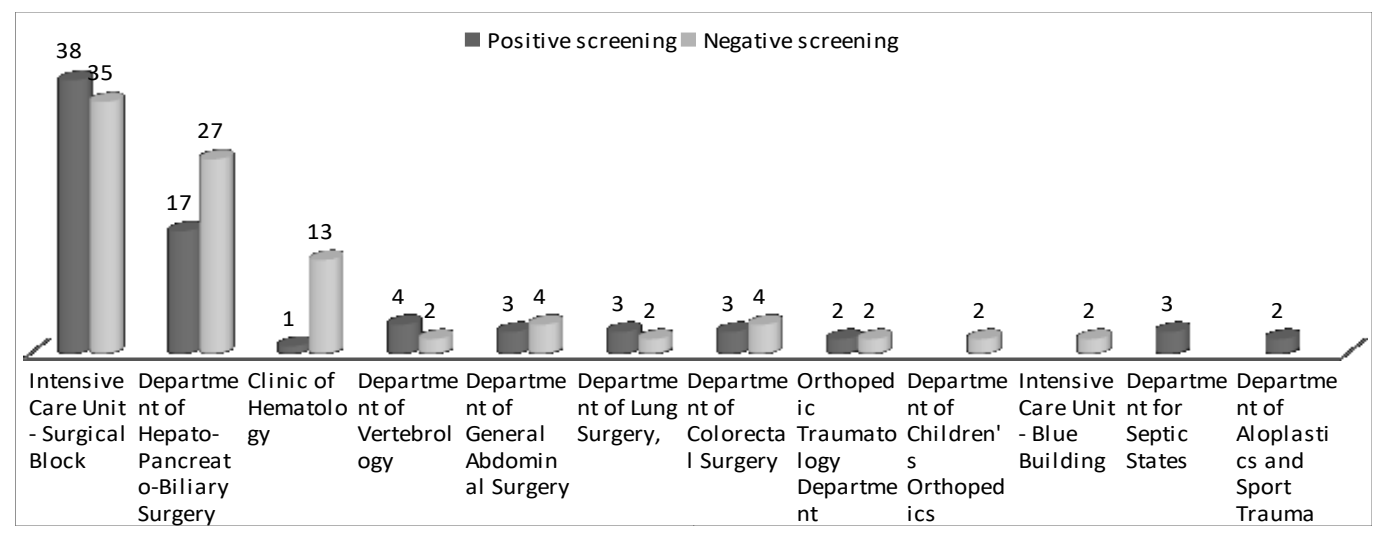

Figure 1. Screening result by the department at the University Clinical Center Tuzla. 
The average time of completion of screening was $\mathbf{2 . 2}$ days or 53 hours.

For $17 / 93(18.27 \%)$ of patients with negative screening results, regular microbiological testing was conducted before screening, mainly serological analysis of influenza and hepatitis, and tests for tuberculosis, while for $76 / 93(81.72 \%)$ screening was done first. In $18 / 76$ $(23.68 \%)$ of patients with positive screening, prior to screening, microbiological testing was performed and for the remaining $58 / 76$ ( $76.3 \%)$ screening was done first. A student's t test showed a statistically significant difference $(\mathrm{P}=0.0316 ; \mathrm{t}=5.4915 ; \mathrm{df}=2)$ between the group of subjects with positive and negative screening versus the time of screening completion.

\section{Negative screening}

After obtaining negative screening results, from wound swabs, aspirates, surgical drain contents and hemocultures of $13 / 93(13.9 \%)$ of patients MDR bacteria were isolated. There were 8 ESBL-producing $K$. pneumoniae, 2 ESBL-producing E. coli and 7 CARBAproducing Acinetobacter isolated. The patients were hospitalized at the Intensive Care Unit - Surgical Block (8/13), Hepato-Pancreato-Biliary Surgery (2/13), Colorectal Surgery (2/13) and Children's Orthopedics $(1 / 13)$.

After negative screening results, one patient had ESBLproducing $K$. pneumoniae isolated from the surgical drain content swab, and in the second screening, of the same patient, the same strain of $K$. pneumoniae was isolated from the inguinal swab. All isolated strains of ESBL-producing $K$. pneumoniae were susceptible to amikacin, imipenem and meropenem, and resistant to ampicillin, amoxicillin/clavulanate, cefazoline, cefuroxime, cefotaxime, cefepime, tobramycin, trimethoprim/sulfamethoxazole, ciprofloxacin, and levofloxacin (Table 2). CARBA-producing Acinetobacter was in all isolates susceptible to colistin and had a variable susceptibility to tobramycin and ampicillin/sulbactam. ESBL-producing E. coli strains were all sensitive to amikacin, trimethoprim/ sulfamethoxazole, imipenem, and meropenem.

\section{Positive screening}

Analysis of one isolate from each examinee (some had more than one positive, with one or two different types of isolated bacteria), showed that ESBL-producing K. pneumoniae was isolated from $23 / 76$ (30.26\%) of patients, CARBA-producing $K$. pneumoniae $13 / 76$ (17.10\%), CARBA-producing Acinetobacter spp. 31/76 (40.78\%), ESBL-producing E. coli 6/76 (7.89\%), ESBL-producing Enterobacter spp. 6/76 (7.89\%), CARBA-producing Enterobacter spp. 4/76 (5.26\%), ESBL-producing Proteus mirabilis (P. mirabilis) 9/76 (11.84\%), AmpC -producing Escherichia coli 1/76 (1.31\%) and MRSA $1 / 76$ (1.31\%). During the seven months of regular screening of patients at UCC Tuzla, out of 76 patients with positive screening test results, a total of 116 samples of MDR bacteria were isolated (Table 1).

Table 1. Distribution of MDR isolates by type of resistance during seven months of study

\begin{tabular}{|c|c|c|c|c|c|c|c|}
\hline & $\begin{array}{l}\text { october } \\
2018 .\end{array}$ & $\begin{array}{l}\text { november } \\
2018 .\end{array}$ & $\begin{array}{l}\text { december } \\
2018 .\end{array}$ & $\begin{array}{l}\text { february } \\
2019 .\end{array}$ & $\begin{array}{l}\text { march } \\
2019 .\end{array}$ & april 2019. & TOTAL \\
\hline $\begin{array}{l}\text { CARBA }+ \\
\text { Acinetobacter spp. }\end{array}$ & 6 & 3 & 6 & 6 & 4 & 3 & 34 \\
\hline $\begin{array}{l}\text { CARBA + } \\
\text { Klebsiella } \\
\text { pneumoniae }\end{array}$ & 8 & 4 & 3 & 1 & 1 & 1 & 18 \\
\hline $\begin{array}{l}\text { CARBA }+ \\
\text { Enterobacter } \text { spp. }\end{array}$ & 2 & - & - & 2 & - & - & 4 \\
\hline $\begin{array}{l}\text { CARBA + } \\
\text { Pseudomonas } \\
\text { aeruginosa }\end{array}$ & - & - & - & 1 & - & - & 1 \\
\hline $\begin{array}{l}\text { ESBL }+ \text { Klebsiella } \\
\text { pneumonia }\end{array}$ & 3 & 2 & 6 & 6 & 6 & 1 & 32 \\
\hline $\begin{array}{l}\text { ESBL+ Escherichia } \\
\text { coli }\end{array}$ & 3 & 1 & - & - & - & - & 6 \\
\hline $\begin{array}{l}\text { ESBL + Enterobacter } \\
\text { spp. }\end{array}$ & 2 & 1 & 1 & - & 1 & - & 6 \\
\hline $\begin{array}{l}\text { ESBL + Proteus } \\
\text { mirabilis }\end{array}$ & 1 & 1 & - & 2 & 3 & 1 & 12 \\
\hline $\begin{array}{l}\text { AmpC }+ \text { Escherichia } \\
\text { coli }\end{array}$ & 1 & - & - & - & - & - & 1 \\
\hline MRSA & & & & 2 & - & - & 2 \\
\hline Total & 26 & 12 & 16 & 20 & 15 & 6 & 116 \\
\hline
\end{tabular}


Analyzing respondents with positive screening, 27 $(35.53 \%)$ had negative results of regular microbiological testing of different biological samples; for 19 (25\%) different strains of MDR bacteria were isolated from aspirates, wound swabs and drain contents, and for $30(39.47 \%)$ the same strain of MDR bacteria, as by screening, was isolated from various biological samples. The Chi squared test found a statistically significant difference in the number of subjects with positive screening and negative microbiological findings compared to respondents with positive screening and isolation of the same or different types of MDR bacteria from other biological samples of the same patients ( $\mathrm{p}$-value is .ooo359; Chi square test = 12.7368)

\section{Positive screening and negative microbiological testing}

From swabs taken from the nose, axilla, groin and anorectal areas 9/27 (33.33\%) ESBL-producing $K$. pneumoniae, $5 / 27(18.51 \%)$ CARBA-producing $K$. pneumoniae, $10 / 27 \quad(37.03 \%) \quad$ CARBA-producing Acinetobacter spp., 2/27 (7.4\%) ESBL-producing $P$. mirabilis and 1/27 (3.7\%) ESBL-producing E. coli were isolated.

\section{Positive screening and different strains of MDR bacteria isolated from aspirates, wound swabs and surgical drain contents}

Out of a total of 76 samples with positive screening test results, 19 had positive screening and different strains of MDR bacteria isolated from biological samples.

After the screening and isolation of ESBL-producing $K$. pneumoniae, P. mirabilis, Enterobacter spp., CARBAproducing Acinetobacter was isolation from aspirates and surgical drain contents for 5/19 (26.31\%) of patients. From axilla and inguinal swabs, taken from one patient $(5.26 \%)$ on two consecutive days, MRSA was isolated and additionally from the inguinal swab ESBL-producing $K$. pneumoniae. The same strain of K. pneumoniae and CARBA-producing Acinetobacter were isolated from subsequent urine cultures of the same patient.

Furthermore, following the isolation of CARBAproducing Acinetobacter from throat, axilla and groin swabs, in $3 / 19(15.78 \%)$ of subjects, ESBL-producing Enterobacterales (K. pneumoniae, $P$. mirabilis, E. coli) were isolated from wound swabs of the same patients. After the isolation of CARBA-producing Enterobacter spp., K. pneumoniae and $P$. aeruginosa for $5 / 19$ (26.31\%) of patients during screening, CARBA-producing Acinetobacter was isolated from the aspirates and surgical drain contents.

For 4/19 (21.05\%) patients, after the isolation of ESBLproducing Enterobacter spp., K. pneumoniae and $P$. mirabilis during screening, subsequently other ESBLproducing Enterobacterales (Enterobacter spp., E. coli and $P$. mirabilis) were isolated from wound swabs.
Positive screening and isolation of the same strain(s) of MDR bacteria from aspirates, wound swabs and surgical drain contents

Out of a total of 76 positive screening test results, 30 (39.47\%) patients had the same strain of MDR bacteria isolated during screening and from various biological samples during regular microbiological testing.

Out of a total of 30 patients with positive screening results, from 12/30 (40\%) MDR K. pneumoniae was isolated, of which 7/12 (58.33\%) was ESBL-producing $K$. pneumoniae and 5/12 (41.66\%) CARBA-producing $K$. pneumoniae.

After obtaining positive screening results for samples taken from the axilla and inguinal regions (ESBLproducing $K$. pneumoniae), for $4 / 12$ (33.33\%) of patients besides the same strain of Klebsiella, CARBAproducing Acinetobacter spp. was isolated from wound swabs.

For 2/12 (16.66\%) of patients after positive screening test results and isolation of CARBA-producing $K$. pneumoniae from axilla and inguinal swabs, the same strain of Klebsiella and CARBA-producing Acinetobacter spp. were isolated from the urine cultures and surgical drain content.

The same strain of ESBL-producing $K$. pneumoniae was isolated from axilla and inguinal regions for 3/12 (41.66\%) of patients, and also from sputum, abdominal and thoracic drain contents.

After obtaining positive screening results by isolating CARBA-producing $K$. pneumoniae from axilla regions and throat swabs for $2 / 12(16.66 \%)$ of patients, subsequently from wound swabs, besides the same strain of Klebsiella, ESBL-producing K. pneumoniae was isolated.

One patient $(1 / 12 ; 8.33 \%)$ had, after the positive screening results of groin area (CARBA-producing $K$. pneumoniae), the same strain of Klebsiella isolated from the wound swab and surgical drain content.

For 12/30 patients who in screening (positive screening and isolation of the same strain(s) of MDR bacteria) had CARBA-producing Acinetobacter spp., screening was performed first for 6 of them.

For 8/12 (66.66\%) of patients who had CARBAproducing Acinetobacter spp. isolated during screening, the same strain was isolated from the wound swabs, surgical drain contents, sputum, aspirate and urine cultures.

For $4 / 12(33.33 \%)$ of patients with CARBA-producing Acinetobacter spp. and ESBL-producing K. pneumoniae, isolated by screening from axilla and groin swabs, the same strain of Acinetobacter was isolated from wound swabs and urine cultures. 
Of the remaining six patients $(6 / 12,20 \%)$, from three ESBL-producing $P$. mirabilis was isolated, from two ESBL-producing Enterobacter spp. and CARBAproducing Enterobacter spp., and from one AmpCproducing E. coli.

For two patients who in screening and biological samples had ESBL-producing P. mirabilis present, in biological samples also had CARBA-producing Acinetobacter spp.

Types of isolated MDR bacteria from different biological samples of patients with positive screening results

Analyzing the microbiological results obtained from samples of wound swabs, surgical drain contents, aspirates, hemocultures, urine cultures and other biological samples of patients with positive screening, 101 following pathogens were isolated: $38(37.62 \%)$, CARBA-producing Acinetobacter spp.; 9 (8.91\%), CARBA-producing $K$. pneumoniae; 2 (1.98\%), CARBA-producing Enterobacter spp.; 24 (23.76\%), ESBL-producing $K$. pneumoniae; 12 (11.88\%), ESBLproducing P. mirabilis; 8 (7.92\%), ESBL-producing $E$ coli; 7 (6.93\%), ESBL-producing Enterobacter spp.; and one isolate (0.99\%) of ESBL-producing Morganellae morganii.

\section{Antimicrobial susceptibility of MDR isolates from screening}

All isolates of CARBA-producing Acinetobacter spp., $K$. pneumoniae and Enterobacter spp. were susceptible to colistin, and varying resistance to amikacin was recorded for Acinetobacter spp. (85.29\%), K. pneumoniae (55.55\%) and Enterobacter spp. (25\%). Resistance to tobramycin was $52.94 \%$ for CARBA-producing Acinetobacter spp. and 50\% for CARBA-producing Enterobacter spp. Resistance to trimethoprim/sulfamethoxazole was detected for 91.17\% of CARBA-producing Acinetobacter spp. and $66.66 \%$ CARBA-producing $K$ pneumoniae. $38.88 \%$ of CARBA-producing $K$. pneumoniae isolates had an intermediate sensitivity/resistance to imipenem. Resistance to ampicillin/sulbactam was detected in 94.11\% of CARBA-producing Acinetobacter spp. and $25 \%$ CARBA-producing Enterobacter spp. To all other antibiotics shown in Table 2, CARBA-producing isolates of above-mentioned bacteria were resistant.

Table 2: Percentage of antibiotic resistance of MDR isolates from positive screening

\begin{tabular}{|c|c|c|c|c|c|c|c|}
\hline & $\begin{array}{l}\text { Acinetobacter } \\
\text { CARBA }\end{array}$ & $\begin{array}{l}\text { Klebsiella } \\
\text { pneumoniae } \\
\text { CARBA }\end{array}$ & $\begin{array}{l}\text { Enterobacter } \\
\text { CARBA }\end{array}$ & $\begin{array}{l}\text { Klebsiella } \\
\text { pneumoniae } \\
\text { ESBL }\end{array}$ & $\begin{array}{l}\text { Escherichia } \\
\text { coli } \text { ESBL }\end{array}$ & $\begin{array}{l}\text { Enterobacter } \\
\text { ESBL }\end{array}$ & $\begin{array}{l}\text { Proteus } \\
\text { mirabilis } \\
\text { ESBL }\end{array}$ \\
\hline AMP $(10 \mu \mathrm{g})$ & l & 100 & 100 & 100 & 100 & 100 & 100 \\
\hline AMX $(30 \mu \mathrm{g})$ & l & 100 & 100 & 100 & 50 & 83.33 & 100 \\
\hline CAZ $(10 \mu \mathrm{g})$ & l & 100 & 100 & 100 & 100 & 100 & 100 \\
\hline CXM $(30 \mu \mathrm{g})$ & l & 100 & 100 & 100 & 100 & 100 & 100 \\
\hline CTX $(5 \mu \mathrm{g})$ & l & 100 & 100 & 100 & 100 & 100 & 100 \\
\hline FEP $(30 \mu \mathrm{g})$ & l & 100 & 100 & 100 & 100 & 100 & 0 \\
\hline AN $(30 \mu \mathrm{g})$ & 85.29 & 55.55 & 25 & 12.5 & 0 & 16.66 & 100 \\
\hline $\mathrm{TN}(10 \mu \mathrm{g})$ & 52.94 & 100 & 50 & 100 & 66.66 & 83.33 & 100 \\
\hline GN $(10 \mu \mathrm{g})$ & 100 & 100 & 100 & 100 & 66.66 & 33.33 & 100 \\
\hline TXT $(25 \mu \mathrm{g})$ & 91.17 & 66.66 & 100 & 96.87 & 83.33 & 100 & 100 \\
\hline CIP $(5 \mu \mathrm{g})$ & 100 & 100 & 100 & 93.75 & 100 & 50 & 100 \\
\hline $\operatorname{LEV}(5 \mu \mathrm{g})$ & 100 & 100 & 100 & 93.75 & 100 & 50 & 100 \\
\hline IMI $(10 \mu \mathrm{g})$ & 100 & $38.88 \mathrm{I}$ & 100 & 0 & 0 & 0 & 0 \\
\hline MER $(10 \mu \mathrm{g})$ & 100 & 100 & 100 & 0 & 0 & 0 & 0 \\
\hline $\operatorname{COL}(10 \mu \mathrm{g})$ & 0 & 0 & 0 & I & l & / & / \\
\hline $\begin{array}{l}\text { AMP/ } \\
\text { SUL }(10-10 \mu \mathrm{g})\end{array}$ & 94.11 & 100 & 25 & 1 & I & 1 & 1 \\
\hline RIF $(5 \mu \mathrm{g}$ & 100 & 100 & 100 & 1 & / & l & / \\
\hline
\end{tabular}

*AMP: ampicillin; AMX: amoxicillin/clavulonic acid; CAZ: ceftazidime; CXM: cefuroxime; CTX: cefotaxime; FEP: cefepime; AN: amikacin; TN: tobramycin; GM: gentamicin; TXT: trimetoprim/sulfometoxazol; CIP: ciprofloxacin; LEV: levofloxacin; IMI: imipenem; MER: meropenem; COL: colistin; AMP/SUL: ampicillin-sulbactam; RIF: rifampicin. 
All isolates of ESBL-producing $K$. pneumoniae, E. coli and Enterobacter spp. were susceptible to imipenem and meropenem. All ESBL-producing $P$. mirabilis isolates were in addition to these two, also susceptible to cefepime. Resistance to amoxicillin/clavulanate had $50 \%$ of $E$. coli (ESBL) isolates and $83.33 \%$ of Enterobacter spp. (ESBL).

Resistance to amikacin and tobramycin was different for ESBL-producing K. pneumoniae (12.5\%, 100), E. coli (50\%, 66.66\%), and Enterobacter spp. (16.66, 83.33\%). $33.33 \%$ of Enterobacter spp. (ESBL) were resistant to gentamicin, and $96.87 \%$ of $K$ pneumoniae (ESBL) to trimethoprim/sulfamethoxazole.

93.75\% of isolates of $K$. pneumoniae (ESBL) and 50\% of Enterobacter spp. were resistant to ciprofloxacin and levofloxacin. To all other antibiotics listed in Table 2, the ESBL-producing isolates of K. pneumoniae, E. coli, Enterobacter spp., and $P$. mirabilis were resistant.

MRSA isolates were resistant to penicillin and cefoxitin and sensitive to amikacin, gentamicin, rifampicin, trimethoprim/sulfamethoxazole, vancomycin, clindamycin, erythromycin, ciprofloxacin and fusidic acid.

\section{Antimicrobial susceptibility of MDR isolates from biological samples of patients with positive screening}

The difference in resistance of MDR isolates from biological samples of patients with positive screening results was found for amoxicillin/clavulanate, amikacin, tobramycin, imipenem and ampicillin/ sulbactam (Table 3).

Table 3. Percentage of resistance of MDR bacteria isolated from biological samples of patients who underwent screening

\begin{tabular}{|c|c|c|c|c|c|c|c|}
\hline & $\begin{array}{l}\text { Acinetobacter } \\
\text { spp.CARBA }\end{array}$ & $\begin{array}{l}\text { Klebsiella } \\
\text { pneumoniae } \\
\text { CARBA }\end{array}$ & $\begin{array}{l}\text { Enterobacter } \\
\text { spp. CARBA }\end{array}$ & $\begin{array}{l}\text { Klebsiella } \\
\text { pneumoniae } \\
\text { ESBL }\end{array}$ & $\begin{array}{l}\text { Escherichia } \\
\text { coli ESBL }\end{array}$ & $\begin{array}{l}\text { Enterobacter } \\
\text { spp. ESBL }\end{array}$ & $\begin{array}{l}\text { Proteus } \\
\text { mirabilis } \\
\text { ESBL }\end{array}$ \\
\hline AMP $(10 \mu \mathrm{g})$ & / & 100 & 100 & 100 & 100 & 100 & 100 \\
\hline AMX $(30 \mu \mathrm{g})$ & l & 100 & 100 & 100 & 50 & 100 & 100 \\
\hline CAZ $(10 \mu \mathrm{g})$ & / & 100 & 100 & 100 & 100 & 100 & 100 \\
\hline CXM $(30 \mu \mathrm{g})$ & I & 100 & 100 & 100 & 100 & 100 & 100 \\
\hline CTX $(5 \mu \mathrm{g})$ & I & 100 & 100 & 100 & 100 & 100 & 100 \\
\hline FEP $(30 \mu \mathrm{g})$ & I & 100 & 100 & 100 & 100 & 100 & 0 \\
\hline AN $(30 \mu \mathrm{g})$ & 100 & 0 & 50 & 8.33 & 0 & 0 & 100 \\
\hline $\mathrm{TN}(10 \mu \mathrm{g})$ & 71.05 & 100 & 100 & 100 & 50 & 100 & 100 \\
\hline GN $(10 \mu \mathrm{g})$ & 100 & 100 & 100 & 100 & 50 & 100 & 100 \\
\hline TXT $(25 \mu \mathrm{g})$ & 94.73 & 44.44 & 100 & 95.83 & 50 & 100 & 100 \\
\hline CIP $(5 \mu \mathrm{g})$ & 100 & 100 & 100 & 100 & 100 & 100 & 100 \\
\hline $\operatorname{LEV}(5 \mu \mathrm{g})$ & 100 & 100 & 100 & 100 & 100 & 100 & 100 \\
\hline IMI $(10 \mu \mathrm{g})$ & 100 & $100 \mathrm{I}$ & 100 & 0 & 0 & 0 & 0 \\
\hline MER $(10 \mu \mathrm{g})$ & 100 & 100 & 100 & 0 & 0 & 0 & 0 \\
\hline $\operatorname{COL}(10 \mu \mathrm{g}$ & 0 & 0 & 0 & l & l & l & l \\
\hline $\begin{array}{l}\text { AMP/ } \\
\text { SUL }(10-10 \mu \mathrm{g})\end{array}$ & 73.64 & 100 & 50 & I & I & I & I \\
\hline $\operatorname{RIF}(5 \mu \mathrm{g}$ & 100 & 100 & 100 & I & I & I & I \\
\hline
\end{tabular}

*AMP: ampicillin; AMX: amoxicillin/clavulonic acid; CAZ: ceftazidime; CXM: cefuroxime; CTX: cefotaxime; FEP: cefepime; AN: amikacin; TN: tobramycin; GM: gentamicin; TXT: trimetoprim/sulfometoxazol; CIP: ciprofloxacin; LEV: levofloxacin; IMI: imipenem; MER: meropenem; COL: colistin; AMP/SUL: ampicillin-sulbactam; RIF: rifampicin. 


\section{DISCUSSION}

MDRsare often found in the intestines, skinand mucous membranes where they do not cause damage, but can cause infections at other sites in the human body, mostly in immunocompromised patients due to other primary illnesses, injuries or previous hospitalizations. Early detection of patients colonized or infected with MDR Gram-negative and Gram-positive bacteria is important for effective management of their status and for timely interventions to prevent the subsequent spread of resistant bacteria. Screening is divided into conventional, where detection of resistant bacterial types is achieved by phenotypic methods, and rapid screening, based on molecular detection of genes that encode resistance to multiple antibiotics.

The significance of screening was examined in a multicentric study [12] in which an assessment has been made of the incidence of gastrointestinal colonization with ESBL-producing Enterobacterales in patients with malignancies and risk of subsequent bloodstream infections. Analyzing data from ten different studies, an overall prevalence of colonization was found to be $19 \%$ and examining the geographical regions, $15 \%$ was in Europe and 31\% in Asia. It has also been found in this study that patients with malignancies colonized with ESBL-producing Enterobacterales are by 12.98 times more likely to develop sepsis than uncolonized. For this reason, screening measures need to be evaluated to determine their clinical benefit.

Active screening represents an overview of asymptomatic patients to detect colonization with the investigated pathogen(s) and may be of utmost importance in determining colonization with MDR bacteria. According to the recommendations of the "Joint Working Group", University College London Hospitals, UK, active screening is advised and not passive surveillance of high risk cases, which include patients with isolated CARBA-producing Gramnegative bacteria from rectal and wound swabs, hospitalized at the Intensive Care Units (ICUs) or referred to by adult care institutions (e.g. nursing homes).

Screening for MDR Enterobacterales and P. aeruginosa should be performed using rectal swabs (with visible material) or stool samples (and urine sample if a catheter is present). For screening of Acinetobacter, samples of skin swabs should be taken or urine, if a catheter is used or respiratory mucus if endotracheal tube is used. Patients who have not been identified as resistant bacteria carriers should be re-screened weekly even after leaving affected hospital units until new cases with negative screening results are identified for more than seven days after the discharge of a resistant bacteria carrier. After obtaining positive screening test results, it is necessary to take precautionary measures and place infected and colonized patients in single rooms if available or cohort patients in the following order of priority: CARBA-producing Enterobacterales,
CARBA-producing Acinetobacter baumannii (A. baumannii), ESBL-producing Klebsiella spp., CARBAproducing $P$. aeruginosa, ESBL-producing $E$. coli and other Enterobacterales, and AmpC-producing Enterobacterales [13].

In addition to the above-mentioned measures, contact precautions are very important because, despite the application of such recommendations, a steady increase in ESBL-producing E. coli and $K$. pneumoniae has been recorded globally. This trend is of particular concern, because the ESBL-producing Enterobacterales exhibit a reduced response rate to antimicrobial treatment, resulting in increased use of carbapenems, which promotes the formation of bacteria resistant to the same. It is considered that the transmission rate is at least two times higher in patients colonized with ESBL-producing $K$. pneumoniae than those colonized with ESBL-producing E. coli. Among patients sharing a common room in intensive care units, the likelihood they will be colonized or infected with ESBL-producing $E$. coli if only one patient is already colonized is $2.6 \%$ while in hospital for geriatric rehabilitation it is $8.6 \%$, with an increase in transmission with the duration of room sharing [14].

In our study of 76 patients with positive screening test results, from 23 of them, ESBL-producing $K$. pneumoniae was isolated and from 9 the same strain was isolated from different biological material (when regular microbiological testing was conducted). From 6 patients with positive screening and isolated ESBLproducing $E$. coli, only for one examinee, the same strain was also isolated from various biological samples. From the results, it could be seen that in our study the percentage of K. pneumoniae (ESBL) transmission from colonization to isolation in biological samples (39.13\%) was higher than E. coli (ESBL; 16.66\%). Of 23 patients, for 6 of them, ESBL-producing $K$. pneumoniae was isolated from several types of screened material, while ESBL-producing E. coli was found in only one sample. Using universal screening by examining swabs taken from throat, axilla and groin area from patients being admitted to intensive care unit in Cairo (Egypt), Fouda et al. [15] showed colonization with ESBL-producing Enterobacterales (33\%), MDR Gram-negative bacteria (13\%) and MRSA (63\%), and higher mortality of MDR colonized patients in intensive care units. Colonization with ESBL-producing Enterobacterales in our study was found in $26.03 \%$ (44/169) of patients, $18.34 \%$ (31/169) with CARBA-producing Acinetobacter spp., $10.05 \%$ (17/169) with CARBA-producing K. pneumoniae and Enterobacter spp., and $0.59 \%(1 / 169)$ with MRSA.

Huskins et al investigating the importance of screening of patients at the admission to intensive care units did not find the reduced prevalence of MRSA and VRE despite the precautionary measures of prevention undertaken for colonized patients [16]. However, according to reports from the United States Agency for Research and Quality in Healthcare, it was established that the application of universal screening of MRSA 
carriers at the admission to intensive care units significantly reduces the risk of MRSA infections [17].

Discordance in the assessment of the significance of screening according to numerous authors is related to the non-uniformed reporting method of isolation and identification of MDR bacteria from throat swabs, axilla, groin and anorectal areas, as well as to following the recommendations of conducting screening for all high-risk patients at the moment of admission to intensive care units. It is recommended that the screening test should be completed for less than 48 hours, and after 24 hours preliminary results using fast phenotypic methods should be reported [18]. In our research, the average screening time was 53 hours (2.2 days). The reason for this slight deviation from recommendations is the dynamics of the process of receiving the material and issuing the results. We also found that there was a statistically significant difference ( $p=0.0316$ ) between the group of patients with positive and negative screening test results in terms of the time of sampling the material for screening (screening of patients before/after entering the intensive care unit). This certainly indicates the importance of timely screening in preventing the spread of resistant bacteria. A certain number of our patients had regular microbiological testing done prior to screening, and an explanation for this is that the patients in our study were hospitalized in different departments at the UCC Tuzla, not just the Intensive Care Unit.

The phenotypic profile of MDR antibiotic bacteria is constantly changing. The global spread of CARBAproducing $K$ pneumoniae, and the use of colistin as a therapeutic option has led to the development of resistance to this antibiotic in many countries in Europe (Italy, Greece, Hungary, Turkey), as well as the United States. Analyzing data from 21 hospitals on resistance of CARBA-producing $K$. pneumoniae isolates, Moneco et al [19] found that $43 \%$ of isolates were resistant to colistin, $16 \%$ to gentamicin, $82 \%$ to trimethoprim/sulfamethoxazole, $6 \%$ to tigecycline and $1 \%$ to all four antibiotics. In our study, we did not find resistance to colistin, while all isolates of CARBAproducing $K$. pneumoniae and Enterobacter spp. were resistant to gentamicin. Resistance to trimethoprim/ sulfamethoxazole was found in $55.55 \%$ of CARBAproducing $K$. pneumoniae isolates.

Increased resistance of $A$. baumannii isolates from clinical sample were recorded throughout Europe. Maraki et al [20] found a significant increase in $A$. baumannii resistance during the period from 2010 to 2014 to imipenem $(72 \%$ to $88.9 \%)$, meropenem $(37.9 \%$ to $89.4 \%)$, gentamicin $(41.7 \%$ to $84.2 \%)$, tobramycin $(59.3 \%$ to $77.8 \%)$, tetracycline $(67.8 \%$ to $90.5 \%$ ), tigecycline ( $2.9 \%$ to $41.3 \%$ ), and colistin (o\% to $7 \cdot 9 \%)$. Significant reductions in resistance were found to amikacin $(76.8 \%$ to $42.9 \%)$ and trimethoprim/ sulfamethoxazole ( $91.5 \%$ to $59.3 \%$ ). The most common A. baumannii phenotype, reported in this study, was resistance to ampicillin/sulbactam, cephalosporins, carbapenems, aminoglycosides, ciprofloxacin, and tigecycline.

CARBA-producing Acinetobacter isolated in our study by screening were resistant to all tested antibiotics (100\%), except for amikacin (85.29\%), tobramycin (52.94\%), trimethoprim/sulfamethoxazole (91.17\%), ampicillin/sulbactam (94.11\%). Isolates from clinical specimens of the same patients, obtained during the regular microbiological testing, showed higher resistance to tobramycin (71.05\%) and trimethoprim/ sulfamethoxazole (94.73\%) and lower to ampicillin/ sulbactam $(73.64 \%)$.

\section{CONCLUSION}

Awareness of the need for active screening of colonized patients to prevent the spread of multi-resistant bacteria is essential for patients as well as for the management of health care institutions. Analyzing our data we found that it is very important to follow the rule of active screening of patients before entering the intensive care unit. Colonization of patients is often caused by two or even three different types of MDR bacteria and the highest percentage of transmission of these bacteria from the place/site of screening to other body sites of the same patient where the infection was found, is for ESBL-producing $K$. pneumoniae and CARBA-producing Acinetobacter spp. Greater resistance was found for MDR bacteria isolated from different biological samples (during regular microbiological testing) than those detected during screening.

\section{REFERENCES:}

1. Magiorakos AP, Srinivasan A, Carey RB, Carmeli Y, Falagas ME, Giske CG, Harbarth S, Hindler JF, Kahlmeter G, Olsson-Liljequist B, Paterson DL, Rice LB, Stelling J, Struelens MJ, Vatopoulos A, Weber JT, Monnet DL. Multidrug-resistant, extensively drugresistant and pandrug-resistant bacteria: an international expert proposal for interim standard definitions for acquired resistance. Clin Microbiol Infect. 2012 Mar; 18(3): 268-81.

2. Siedelman L, Kline S, Duval S. Risk factors for community- and health facility-acquired extended-spectrum-lactamase-producing bacterial infections in patients at the University of Minnesota Medical Center, Fairview. Am J Infect Control 2012; 40: 849e853.

3. Mitchell SL, Shaffer ML, Loeb MB, Givens JL, Habtemariam D, Kiely DK, D’Agata E. Infection management and multidrugresistant organisms in nursing home residents with advanced dementia. JAMA Intern Med. 2014 Oct; 174(10): 1660-7.

4. Feldman N, Adler A, Molshatzki N, et al. Gastrointestinal colonization by KPCproducing Klebsiella pneumoniae following hospital discharge: duration of carriage 
and risk factors for persistent carriage. Clin Microbiol Infect. 2013; 19: E19oeE196.

5. Ena J, Arjona F, Martinez PC, Lopez-Perezagua MD, Amador C. Epidemiology of urinary infections caused by extended-spectrum beta-lactamase-producing Escherichia coli. Urology 2014; 68: 1169e1174.

6. Ren Y, Ma G, Peng L, Ren Y, Zhang F. Active screening of multi-drug resistant bacteria effectively prevent and control the potential infections. Cell Biochem Biophys. 2015 Mar; 71(2): 1235-8.

7. European Committee on Antimicrobial Susceptibility Testing, Breakpoint tables of interpretation of MIC's and zone diameters Version 8.o, 2018; http://www.eucast.org.

8. Viau R, Frank KM, Jacobs MR, et al. Intestinal Carriage of Carbapenemase-Producing Organisms: Current Status of Surveillance Methods. Clin Microbiol Rev. 2016; 29(1):1-27.

9. Clinical and Laboratory Standards Institute. Performance Standards for Antimicrobial Susceptibility Testing. 2014; M100-S24(34): 64-65.

10. Muthusamy D, Sudhishnaa S, Boppe A. Invitro Activities of Polymyxins and Rifampicin against Carbapenem Resistant Acinetobacter baumannii at a Tertiary Care Hospital from South India. J Clin Diagn Res. 2016; 10(9): DC15-DC18.

11. Ruangkriengsin D, Pati N, Maknakhon N, Tan-arsuwongkul R, Jumderm C, Tiengrim S, Thamlikitkul. Comparative Colistin Susceptibility Testing Methods for Escherichia coli and Klebsiella pneumonia V J Med Assoc Thai 2018; 101(12): 1666-79.

12. Alevizakos M, Karanika S, Detsis M, Mylonakis E. Colonisation with extended-spectrum $\beta$-lactamase-producing Enterobacteriaceae and risk for infection among patients with solid or haematological malignancy: a systematic review and meta-analysis. Int J Antimicrob Agents. 2016 Dec; 48(6): 647-654.

13. Wilson AP, Livermore DM, Otter JA, Warren RE, Jenks P, Enoch DA, Newsholme W, Oppenheim B, Leanord A, McNulty C, Tanner G, Bennett S, Cann M, Bostock J,Collins E, PeckittS, Ritchie L, Fry C, Hawkey P. Prevention and control of multi-drug-resistant Gramnegative bacteria: recommendations from a Joint Working Party. J Hosp Infect. 2015 Jan; 92 Suppl 1: S1-44.

14. Tschudin-Sutter S, Lucet JC, Mutters NT, Tacconelli E, Zahar JR, Harbarth S. Contact Precautions for Preventing Nosocomial Transmission of Extended-Spectrum $\beta$ Lactamase-Producing Escherichia coli: A Point/Counterpoint Review. Clin Infect Dis. 2017 Jul; 65(2): 342-347.

15. Fouda R, Soliman MS, ElAnany MG, Abadeer M, Soliman G. Prevalence and risk factors of MRSA, ESBL and MDR bacterial colonization upon admission to an Egyptian medical ICU. J Infect Dev Ctries. 2016 Apr; 10(4): 329-36.

16. Huskins W, Huckabee C, O'Grady N, Murray P, Kopetskie H, Zimmer L, Walker M, SinkowitzCochran R, Jernigan J, Samore M, Wallace $\mathrm{D}$, Goldmann $\mathrm{D}$. Intervention to reduce transmission of resistant bacteria in intensive care. N Engl J Med. 2011; 364: 1407-1418.

17. Glick S, Samson D, Huang E, Vats V, Weber $\mathrm{S}$, Aronson N. Screening for MethicillinResistant Staphylococcus aureus (MRSA). Comparative Effectiveness Reviews, No. 102. Rockville (MD) 2013; Agency for Healthcare Research and Quality (US).

18. García M, Cornejo A, León D and Arenas M. Current Status of Colonization and Infection by Multiresistant Bacteria in the Spanish Intensive Care Unit: Resistence Zero Program. 2018; 10.5772/intechopen.78236.

19. Monaco, M., Giani, T., Raffone, M., Arena, F., Garcia-Fernandez, A., Pollini, S., et al. Colistin resistance superimposed to endemic carbapenem-resistant Klebsiella pneumoniae: a rapidly evolving problem in Italy, Euro. Surveill. 2014; 19: 20939.

2o. Maraki S, Mantadakis E, Mavromanolaki VE, Kofteridis DP, Samonis G. A 5-year Surveillance Study on Antimicrobial Resistance of Acinetobacter baumannii Clinical Isolates from a Tertiary Greek Hospital. Infect Chemother. 2016; 48(3):190-198.
Scan this QR code with your mobile device for instant access to the current Issue of Acta Medica Saliniana

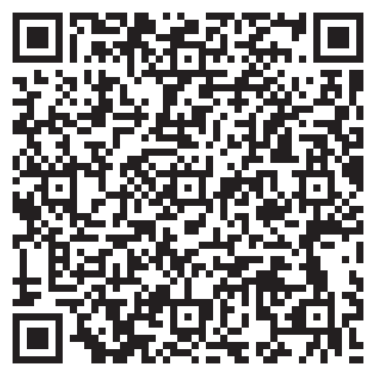

